\title{
Edukasi Identifikasi Masa Kadaluarsa Obat dan Perhitungan Beyond Use Date pada Pasien Instalasi Farmasi Rawat Jalan di RSUD dr. $\mathbf{R}$. Koesma Kabupaten Tuban
}

\author{
Iskandar $^{1}$, Byba Meida ${ }^{2}$, Devi Ristian Octavia ${ }^{3 *}$ \\ ${ }_{1,2}$ Institut Ilmu Kesehatan Strada Indonesia, Kediri, Indonesia \\ ${ }^{3}$ Universitas Muhammadiyah, Lamongan, Indonesia \\ *Corresponding Author: devioctavia1987@gmail.com
}

Info Artikel Diterima: 05/02/2022 Direvisi: 09/02/2022 Disetujui: 10/02/2022

\begin{abstract}
Public knowledge about health, especially medicine is still very limited. One of the terms of health in medicine that is less known by the public is BUD (Beyond Use Date). BUD is time limit for the use of medicinal products after being prepared/formulated or after the primary packaging is opened/tampered with. While ED (Expiration Date) is the time limit for the use of medicinal products after being produced by the manufacturer before the packaging is opened. ED is listed by the manufacturer on the packaging while BUD is not always listed. Providing correct information about BUD becomes the needs of the community to avoid negative impacts that may arise,such as: the occurrence of medication error, the target therapy is not optimal and decreases the effectiveness of the medicinal products. For this reason, an effort is needed to increase public knowledge about $B U D$, namely through counseling activities with lecture, discussion and Q\&A methods. Counseling on BUD (Beyond Use Date) in patients of Hospital Outpatient Pharmacy Installationt dr.R.Koesma Tuban Regency, aims to find out the level of public knowledge of BUD. Based on the evaluation results of the pre test question sheet (before counseling) and post test question sheet (after counseling) most of the participants increased their knowledge, its means that the participants understood the definition and the difference between BUD and ED solid, semi-solid, liquid, eye drops and insulin preparations.
\end{abstract}

Keywords: Beyond Use Date, Education, Expired Date.

\begin{abstract}
Abstrak. Pengetahuan masyarakat mengenai dunia kesehatan, terutama obat masih sangat terbatas. Salah satu obat yang kurang dikenali oleh masyarakat yaitu mengenai BUD (Beyond Use Date ). BUD adalah batas waktu penggunaan produk obat setelah diracik/disiapkan atau setelah kemasan primernya dibuka/dirusak. Sedangkan ED (Expired Date) adalah batas waktu penggunaan produk obat setelah diproduksi oleh pabrikan sebelum kemasannya dibuka. Penulisan ED dicantumkan oleh pabrikan pada kemasan sementara BUD tidak selalu tercantum. Pemberian informasi yang benar mengenai BUD menjadi kebutuhan masyarakat agar terhindar dampak negative yang mungkin timbul antara lain: terjadinya medication error, target terapi tidak optimal serta menurunkan efektifitas obat tersebut. Untuk itu perlu dilakukan suatu upaya untuk meningkatkan pengetahua masyarakat tentang BUD yaitu melalui kegiatan penyuluhan dengan metode ceramah,diskusi dan tanya jawab. Penyuluhan tentang BUD (Beyond Use Date) pada pasien Instalasi Farmasi Rawat Jalan RSUD dr.R.Koesma Kabupaten Tuban bertujuan untuk mengetahui tingkat pengetahuan masyarakat terhadap BUD. Berdasarkan hasil evaluasi penilaian lembar soal pre test (sebelum penyuluhan) dan post test (setelah penyuluhan) sebagian besar peserta meningkat pengetahuannya, artinya peserta memahami pengertian serta perbedaan BUD dan ED sediaan padat,semi padat,cair,tetes mata maupun insulin..
\end{abstract}

Kata Kunci: Beyond Use Date, Edukasi, Kadaluarsa Obat.

How to Cite: Iskandar, I., Meida, B., \& Octavia, D. R. (2022). Edukasi Identifikasi Masa Kadaluarsa Obat dan Perhitungan Beyond Use Date pada Pasien Instalasi Farmasi Rawat Jalan di RSUD dr. R. Koesma Kabupaten Tuban. Prima Abdika: Jurnal Pengabdian Masyarakat, 2(1), 55-61. https://doi.org/10.37478/abdika.v2i1.1689

Copyright (c) 2022 Iskandar, Byba Meida, Devi Ristian Octavia. This work is licensed under a Creative Commons Attribution-ShareAlike 4.0 International License.

\section{Pendahuluan}

Di Indonesia, persentase penyimpanan obat pada skala rumah tangga cukup besar. Masyarakat menyimpan obat untuk swamedikasi (Sari et al., 2021). Dalam pelaksanaannya, swamedikasi yang kurang tepat selain menimbulkan beban bagi pasien, juga menimbulkan masalah kesehatan tertentu yang tidak menguntungkan seperti resistensi obat, efek samping, interaksi obat, termasuk kematian (Devi Ristian; Octavia et al., 2019). Saat 
ini, masyarakat masih sering salah dalam hal mendapatkan, menggunakan, menyimpan dan membuang obat dengan benar. Hal tersebut dapat menyebabkan terjadinya hal yang tidak diinginkan dalam pengobatan seperti obat yang tidak bisa berfungsi optimal (Devi Ristian Octavia et al., 2020). Obat tidak dapat disimpan sembarangan karena akan mempengaruhi stabilitas obat (Sari et al., 2021).

Perilaku penyimpanan obat merupakan hal yang biasa dilakukan oleh masyarakat. Namun istilah beyond use date (BUD) dalam penyimpanan obat masih jarang diketahui karena masih terbatasnya penelitian tentang BUD (Pertiwi et al., 2021). Beyond Use Date adalah batas waktu penggunaan produk obat setelah diracik/disiapkan atau setelah kemasan primernya dibuka/dirusak. Kusuma et al., (2020) melaporkan tingkat pengetahuan masyarakat berkaitan dengan Beyond Use Date di Indonesia masih terbilang rendah. Hal serupa dipertegas oleh (Cokro et al., 2021) bahwa Mayoritas informan $(97 \%)$ tidak mengetahui tentang BUD, dan semua informan $(100 \%)$ tidak pernah menerima informasi BUD dari apoteker. Sebagian dari informan memiliki persepsi bahwa BUD sama dengan masa kadaluarsa yang ada di kemasan pabrik. Kami menyimpulkan bahwa persepsi masyakat Jakarta Utara mengenai BUD dapat disebabkan oleh pengetahuan tentang BUD yang rendah, dan peran apoteker dalam menginformasikan dan mengedukasi pasien dan masyarakat mengenai BUD sangat diperlukan.

Salah menafsirkan petunjuk label obat adalah penyebab umum terjadinya kesalahan pengobatan atau medication error dan mempengaruhi hasil kesehatan pasien. Untuk preparat atau produk tanpa persiapan yang telah robek, pelabelan tidak diatur dan tidak terstandar (Wolf et al., 2016). Medication error menyebabkan lebih dari 7.000 kematian per tahun. Medication error adalah jenis kesalahan medis yang sering menyebabkan kerugian pada pengobatan pasien, terutama pada penggunaan obat yang tidak tepat, sehingga menyebabkan bahaya pada pasien (Devi Ristian; Octavia et al., 2021). Oleh karena itu penting untuk mengedukasi masyarakat agar pengetahuan tentang penggunaan dan pengelolaan obat yang baik dapat meningkat.

Peran tenaga kefarmasian di Rumah Sakit telah diatur dalam (pmk no.72, 2016) tentang Standar Pelayanan Kefarmasian di Rumah Sakit, Pelayanan Kefarmasian dibagi menjadi dua yaitu kegiatan pengelolaan Sediaan Farmasi, Alat Kesehatan, dan Bahan Medis Habis Pakai dan kegiatan Pelayanan Farmasi Klinik. Pelayanan Farmasi Klinik terdiri dari beberapa kegiatan salah satunya Pelayanan Informasi Obat (PIO). Pendampingan Apoteker dalam memberikan konsultasi penggunaan obat mampu meningkatkan antusias dan pengetahuan masyarakat tentang penggunaan obat yang baik (Devi Ristian Octavia et al., 2022). Hal serupa juga dipaparkan oleh Devi Ristian Octavia et al., (2020) bahwa pengabdian masyarakat tentang pengelolaan obat yang baik dengan metode CBIA mampu meningkatkan pengetahuan yang signifikan masyarakat terhadap penggunaan obat yang benar. Artikel ini bertujuan untuk mendiskripsikan hasil pengabdian masyarakah tentang edukasi BUD pada pasien Instalasi Farmasi Rumah Sakit dr. Koesma Tuban Jawa Timur. 


\section{Metode Pelaksanaan}

Untuk mencapai tujuan pengabdian, maka kegiatan pengabdian ini dilakukan melalui tiga tahapan sebagai berikut:

1. Tahap Persiapan

Tahap persiapan dilaksanakan dengan cara membentuk tim pengabdian masyarakat yang terdiri dari tenaga kefarmasian yang berpraktik di Instalasi Farmasi RS dr. Koesma Tuban dan mahasiswa program pascasarjana IIK STRADA Indonesia. Pada tahap ini tim pengabdian melakukan identifikasi masalah kepada pasien yang sedang menunggu pelayanan obat rawat jalan. Identifikasi permasalahan dilakukan dengan metode pendekatan dan wawancara secara langsung kepada pasien. Hasil identifikasi masalah didapatkan bahwa mayoritas pasien yang menunggu obat memiliki pengetahuan yang rendah tentang Beyond Use date (BUD)

2. Tahap Pelaksanaan

Pada tahap ini dilakukan dengan metode penyuluhan tentang Batas Waktu Penggunaan Produk Obat Setelah Lepas Dari Kemasan Primer (Beyond Use Date). Kegiatan yang dilaksanakan adalah: Kegiatan penyuluhan tentang BUD dilaksanakan di Instalasi Farmasi Rawat Jalan dengan sasaran pasien atau keluarga pasien yang menunggu pengambilan obat sebagai peserta. Kegiatan dibuka dengan salam, perkenalan dan menjelaskan maksud dan tujuan penyuluhan. Sebelum dilaksanakan penyuluhan, peserta diberi lembar soal pre test untuk mengetahuai pengetahuan peserta tentang BUD. Selanjutnya dilakukan kegiatan penyuluhan menggunakan metode ceramah dengan alat bantu media edukasi leaflet dan video. Materi penyuluhan antara lain; pengertian serta perbedaan BUD dan ED obat sediaan padat, semi padat, sediaan cair, sirup kering, tetes mata dan insulin. Untuk memperdalam materi penyuluhan dibuka sesi diskusi dan tanya jawab.

3. Tahap Evaluasi

Pada tahap ini pasien diberikan lembar postest untuk mengukur pengetahuan pasien setelah dilakukan penyuluhan. Hasil evaluasi penilaian pre test dan post test dibandingkan untuk mengetahui peningkatan pengetahuan.

\section{Hasil dan Pembahasan}

Penyuluhan tentang BUD (Beyond Use Date) diberikan kepada pasien atau keluarga pasien yang sedang antri menunggu obat di Instalasi Farmasi Rawat Jalan RSUD dr.R.Koesma Kabupaten Tuban. Kegiatan penyuluhan diikuti peserta sebanyak 22 orang. Kegiatan ini telah terlaksana dengan baik, melibatkan 1 orang petugas lapangan sebagai penyuluh yang merupakan mahasiswa program pascasarjana IIK STRADA Indonesia bersama dengan karyawan Instalasi Farmasi Rawat Jalan di RSUD dr.R.Koesma Tuban.

Dalam tahap edukasi kepada pasien disampaikan bahwa Saat ini masih banyak ditemukan resep dokter racikan obat terutama untuk anak-anak dan lansia. Obat racikan rentan akan ketidakstabilan oleh karena itu evaluasi secara fisika maupun kimia perlu dilakukan untuk mengevaluasi stabilitas sediaan racikan obat. Penentuan stabilitas pada obat racikan tidak lagi menggunakan keterangan expired date (waktu kedaluwarsa) yang berasal dari 
industri farmasi tetapi menggunakan ketentuan Beyond Use Date (BUD, masa edar) pada karena obat tidak lagi berada pada kemasan aslinya. Beyond Use Date merupakan batas waktu penggunaan racikan obat yang masih dikatakan aman (Rohmanna \& Sukmawati, 2021). Lama penyimpanan obat tergantung dari kandungan dan cara menyimpannya. Obat yang mengandung cairan akan mengalami reaksi peruraian paling cepat, hal ini disebabkan karena bakteri dan jamur dapat tumbuh baik di lingkungan lembab (cair). Dalam obat-obatan biasanya ada kandungan zat pengawet, yang dapat merintangi pertumbuhan bakteri dan jamur. Akan tetapi bila wadah sudah dibuka, maka zat pengawetpun tidak mampu menghindari kerusakan obat secara keseluruhan karena kemasan tidak tertutup rapat lagi (Devi Ristian Octavia et al., 2020).

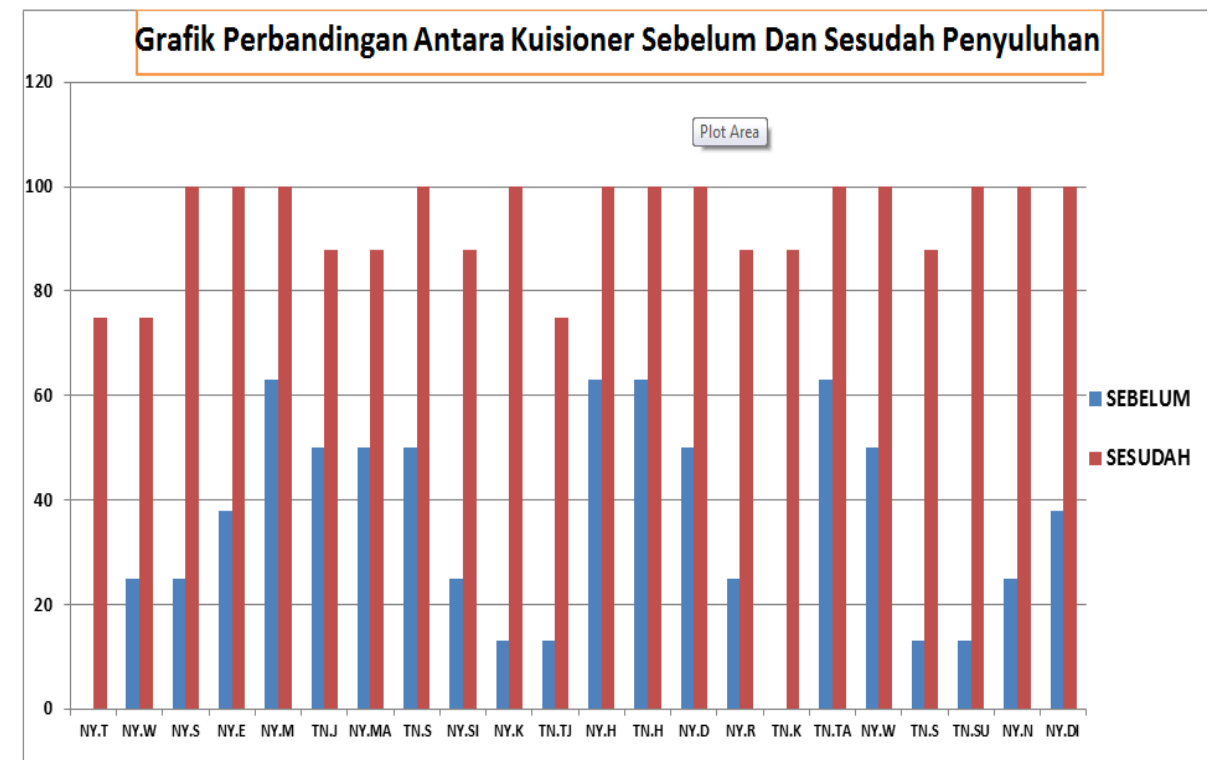

Gambar 1. Grafik Pengetahuan Mitra

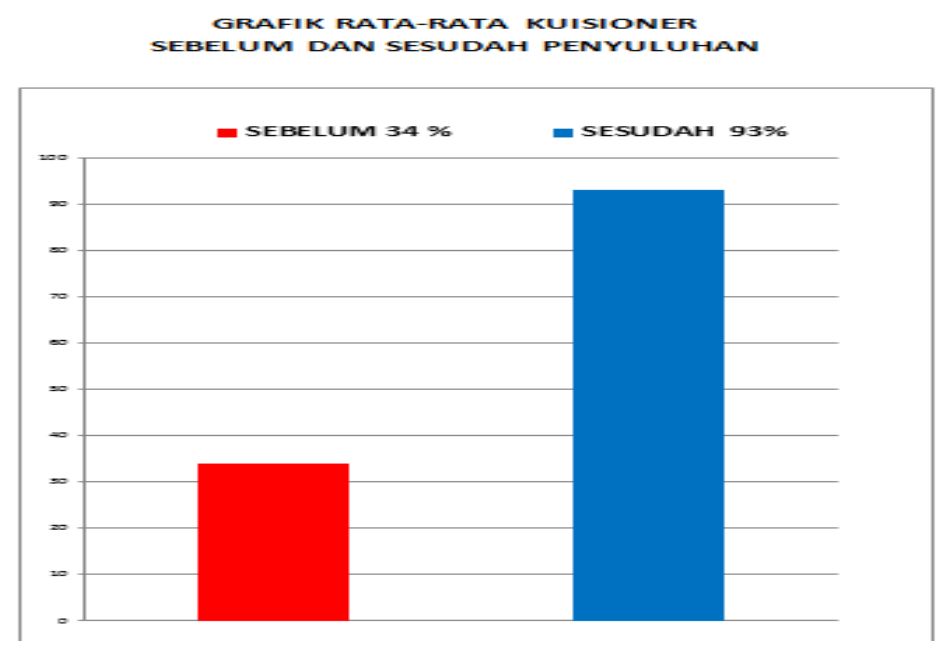

Gambarb 2. Grafik presentase rata-rata kuisioner 
Gambar 1 menunjukkan presentase hasil kuisioner sebelum penyuluhan (pre test) nilai terendah $0 \%$ (2 orang) dan tertinggi 63\% (3orang). Setelah dilakukan penyuluhan untuk melihat pengetahuan peserta terkait BUD didapat nilai prosentase terendah $75 \%$ (3 orang) dan tertinggi $100 \%$ (13 orang). Pada Gambar 2 rata-rata nilai prosentase sebelum penyuluhan adalah $34 \%$ dan nilai sesudah penyuluhan sebesar 93\%. Apoteker adalah salah satu tenaga kesehatan yang memiliki keahlian di bidang obat-obatan. Apoteker memiliki kompetensi dan kewenangan dalam bidang kefarmasian baik yang berpraktik apotek, klinik, industri, rumah sakit, pendidikan,dan bidang lain yang berkaitan dengan ilmu farmasi (Devi Ristian Octavia \& Aisyah, 2019). Pengabdian masyarakat dengan metode penyuluhan mampu memberikan dampak positif bagi peningkatan pengetahuan masyarakat tentang kelola obat yang benar, dengan demikian akan mengurangi efek samping yang tidak dikehendaki serta menjaga keamanan dalam penggunaan obat dan kestabilan obat saat proses penyimpanan (Ariastuti \& Pambudi, 2021).

Dari hasil evaluasi terhadap pre test dan post test tentang BUD ada peningkatan pengetahuan peserta penyuluhan sebesar $59 \%$ yakni dari hasil evaluasi pre test atau sebelum penyuluhan sebesar $34 \%$ sedangkan hasil evaluasi post test atau sesudah penyuluhan sebesar $93 \%$. Faktor-faktor yang mempengaruhi peningkatan pengetahuan antara lain penyampaian materinya cukup jelas, suasana di ruangan yang kondusif, dan media penyampaian materi yang memadai (Kusuma et al., 2020).

Kegiatan pengabdian masyarakat berupa penyuluhan ini berjalan lancar. Peserta mengikuti dengan antusias, banyak pertanyaan yang diajukan terkait BUD disebabkan materi menarik dan baru bagi peserta. Peningkatan pengetahuan tentang BUD antara lain; peserta bisa memahami pengertian serta perbedaan BUD dan ED, BUD dan ED tablet, kapsul, sirup, sirup kering, insulin, tetes mata dan salep kulit. Setelah dilakukan penyuluhan ini masyarakat diharapkan agar lebih berhati - hati dalam penggunaan dan penyimpanan obat. Masyarakat memahami bagaimana bila obat melebihi ED atau BUD serta cara mengatasinya. Setelah pelaksanaan kegiatan penyuluhan, peserta diharapkan dapat membagikan informasi kepada keluarga, tetangga dan masyarakat yang lain tentang BUD (Beyond Use Date).

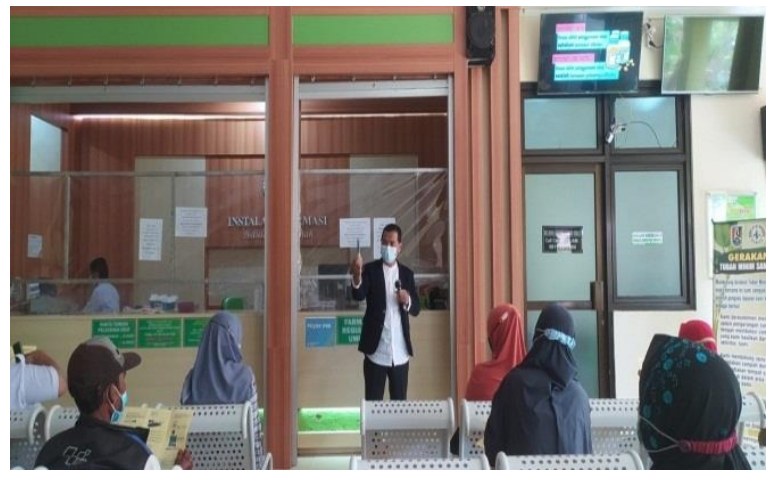

Gambar 1. Dokumentasi Kegiatan Penyuluhan BUD di IFRS dr. Koesma Tuban

\section{Simpulan dan Tindak Lanjut}

Kegiatan penyuluhan BUD (Beyond Use Date) pada Pasien Instalasi Farmasi Rawat Jalan di RSUD dr.R.Koesma Kabupaten Tuban dapat 
meningkatkan pengetahuan masyarakat.Hal ini ditunjukkan dari hasil evaluasi pre test dan post test terjadi peningkatan pengetahuan peserta penyuluhan.

\section{Daftar Pustaka}

Ariastuti, R., \& Pambudi, R. S. (2021). OPTIMALISASI PERAN KADER PKK DESA RANDUREJO DALAM PENGGUNAAN OBAT DENGAN BAIK MELALUI GERAKAN “DAGUSIBU.” Jurnal Pengabdian Al-Ikhlas, 7(2), 180187.

Cokro, F., Arrang, S. T., Solang, J. A. N., \& Sekarsari, P. (2021). The BeyondUse Date Perception of Drugs in North Jakarta, Indonesia. Indonesian Journal of Clinical Pharmacy, 10(3), 172-179. https://doi.org/10.15416/ijcp.2021.10.3.172

Kusuma, I. Y., Octaviani, P., Muttaqin, C. D., Lestari, A. D., Rudiyanti, F., \& Sa'diah, H. (2020). Upaya Peningkatan Pemahaman Masyarakat Terhadap Beyond Use Date Didesa Kecepit, Kecamatan Punggelan, Kabupaten Banjarnegara. Pelita Abdi Masyarakat, 1(1. Pelita Abdi Masyarakat, 1(1), 6-10.

Octavia, Devi Ristian;, Purwandini, S. N., Hilaria, M., \& Pangestu, D. P. (2021). Medication Error at the Prescribing Phase. Jurnal Info Kesehatan, 19(1), 12-19. https://doi.org/10.31965/infokes.Vol19Iss1

Octavia, Devi Ristian;, Zakaria, M. S., \& Nurafifah, D. (2019). Tingkat Pengetahuan Masyarakat Tentang Swamedikasi yang Rasional di Lamongan. Surya, 11(02), 10-16.

Octavia, Devi Ristian, \& Aisyah, M. (2019). Pelatihan Apoteker Cilik Siswa Sekolah Dasar Dalam Upaya Penggunaan Obat Yang Tepat Di Lamongan. JCES (Journal of Character Education Society), 2(2), 1-10. http://journal.ummat.ac.id/index.php/JCES/article/view/1482

Octavia, Devi Ristian, Susanti, I., Bintang, S., Mahaputra, S., Negara, K., Kesehatan, F. I., \& Lamongan, U. M. (2020). PENINGKATAN PENGETAHUAN MASYARAKAT TENTANG PENGGUNAAN DAN PENGELOLAAN OBAT YANG RASIONAL MELALUI PENYULUHAN DAGUSIBU. GEMASSIKA, 4(1), 23-39.

Octavia, Devi Ristian, Susanti, I., Farmasi, P. S.-, Kesehatan, F. I., \& Lamongan, U. M. (2022). Aplikasi AKO (Apoteker Keluarga Online) sebagai Media Digital Counseling dalam Upaya Penggunaan Obat yang Rasional di Masyarakat. PUNDIMAS, $1(1), \quad 1-6$. https://doi.org/https://doi.org/10.37010/pnd.v1i1

Pertiwi, G. S., Aini, S. R., \& Hajrin, W. (2021). Tingkat Pengetahuan Mahasiswa Program Studi Universitas. Jurnal Kedokteran 2021, 10(2), 435-440.

pmk no.72. (2016). Permenkes RI No.72 tahun 2016 (pp. 1-40).

Rohmanna, R. A., \& Sukmawati, A. (2021). Pemantauan Stabilitas Sefiksim pada Sediaan Racikan Pulveres berdasarkan ketentuan Beyond Use Date. 601-607.

Sari, O. M., Anwar, K., Putri, I. P., Farmasi, P. S., Mangkurat, U. L., \& 
Indonesia, D. (2021). Tingkat pengetahuan dalam penyimpanan dan pembuangan obat di rumah pada masyarakat kota banjarbaru kalimantan selatan. Cendekia Journal of Pharmacy STIKES Cendekia Utama Kudus PISSN, 5(2), 145-155.

Wolf, M. S., Davis, T. C., Curtis, L. M., Bailey, S. C., Knox, J. P., Bergeron, A., Abbet, M., Shrank, W. H., Parker, R. M., \& Wood, A. J. J. (2016). A Patient-Centered Prescription Drug Label to Promote Appropriate Medication Use and Adherence. Journal of General Internal Medicine, 31(12), 1482-1489. https://doi.org/10.1007/s11606-016-3816-x 